\title{
Integration of Electrocatalysts with Silicon Microcone Arrays for Minimization of Optical and Overpotential Losses during Sunlight-Driven Hydrogen Evolution
}

Sisir Yalamanchili ${ }^{1,3 \$}$, Paul A. Kempler, ${ }^{2,3}$, Kimberly M. Papadantonakis ${ }^{2,3}$, Harry A. Atwater $^{1,3,4^{*}}$, Nathan S. Lewis ${ }^{2-5^{*}}$

${ }^{1}$ Division of Engineering and Applied Sciences, California Institute of Technology, Pasadena, CA 91125

${ }^{2}$ Division of Chemistry and Chemical Engineering, California Institute of Technology, Pasadena, CA 91125

${ }^{3}$ The Joint Center for Artificial Photosynthesis, California Institute of Technology, Pasadena, CA 91125

${ }^{4}$ Kavli Nanoscience Institute, California Institute of Technology, Pasadena, CA 91125

${ }^{5}$ Beckman Institute, California Institute of Technology, Pasadena, CA 91125

*Corresponding Authors: haa@caltech.edu, nslewis@its.caltech.edu

${ }^{\$}$ Equal Contributions 


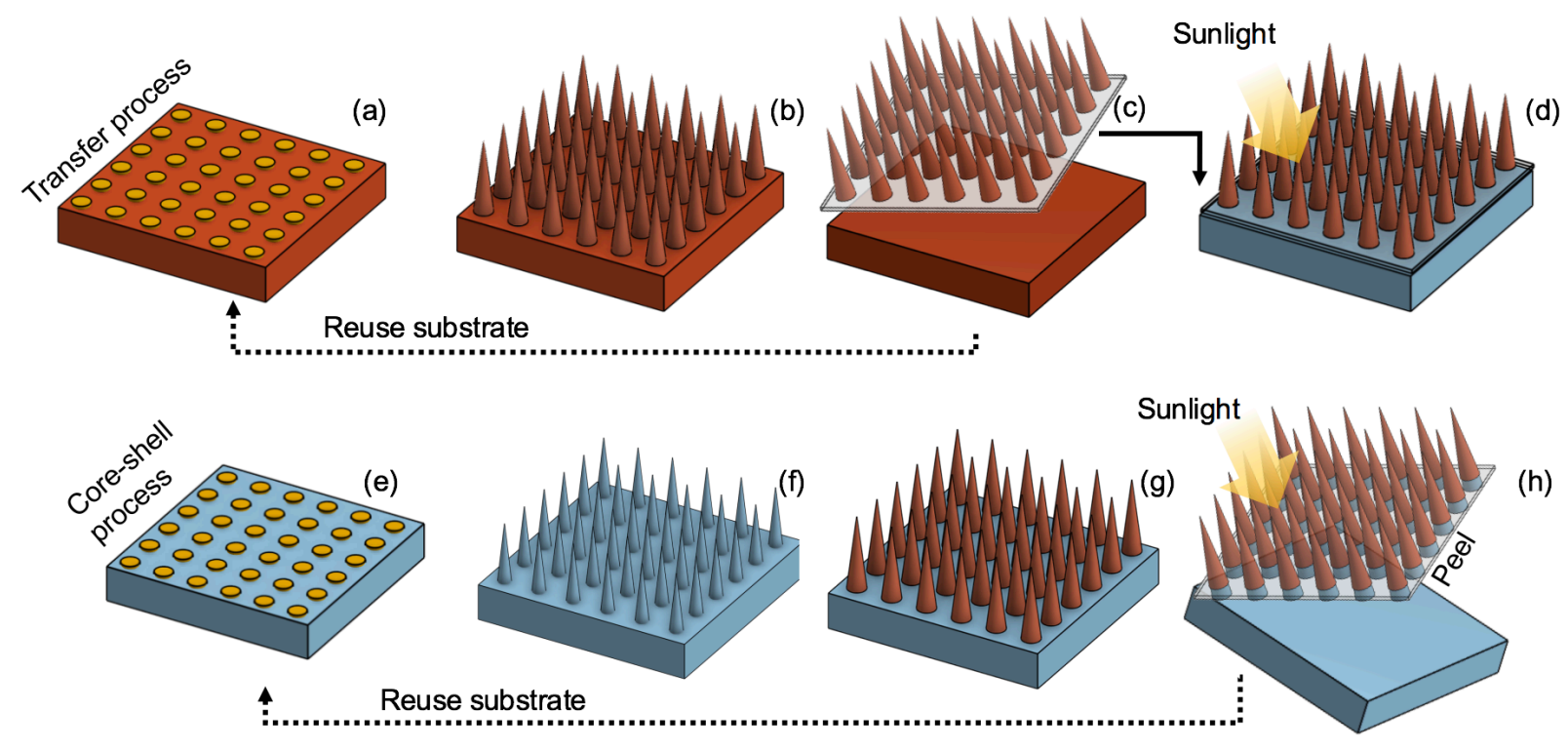

Figure S1: Process flow diagrams for two methods of fabricating integrated solar fuels devices. Scalable integration of a wide band gap top cell with a monolithic Si bottom cell could be achieved via: (a) patterning a crystalline III-V semiconductor substrate with $\mathrm{Au}$ seeds or $\mathrm{Cr}$ masks for vapor-liquid-solid growth or dry etching, respectively; (b) fabricating a micro- or nanocone array via vapor-liquid-solid growth followed by chemical etching or dry etching. ${ }^{1,2}$ (c) embedding the micro- or nanocone array in a flexible polymer, and removing it from the substrate for transfer; ${ }^{1}$ (d) metallizing the array with catalysts and ohmic contacts on the top- and bottom-facing sides, respectively, for integration with a Si bottom cell. Fabrication of a tandem, core-shell microcone array embedded in an ion conducting membrane could be achieved via: (e) patterning a $\mathrm{Si}$ substrate with $\mathrm{Cu}$ seeds or $\mathrm{Al}_{2} \mathrm{O}_{3}$ masks; (f) fabricating a microcone array as in (b), and coating with an ohmic contact such as indium-tin-oxide; (g) depositing a wide band gap semiconductor via metal-organic chemical vapor deposition, ${ }^{3}$ thermochemical conversion from solution, ${ }^{4}$ or electrochemical growth, ${ }^{5}$ on the surface of the microcone array, leading to a coreshell architecture; (d) infilling the arrays with an ion exchange membrane and peeling from the substrate. The substrate can be re-patterned to reduce material demands. 


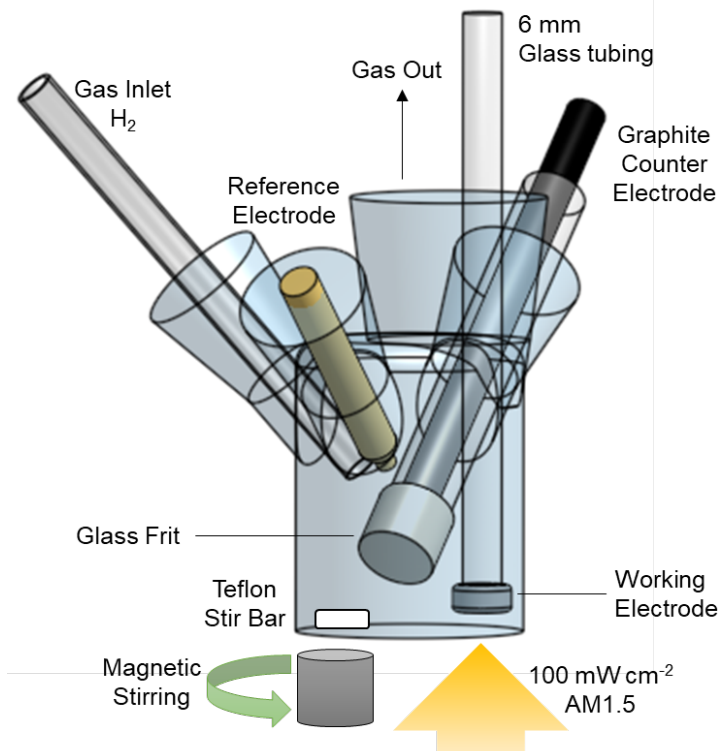

Figure S2: Schematic diagram of the cell used for photoelectrochemical hydrogen evolution testing of devices. Illumination was directed into the base of the cell onto a bottom facing photoelectrode. 


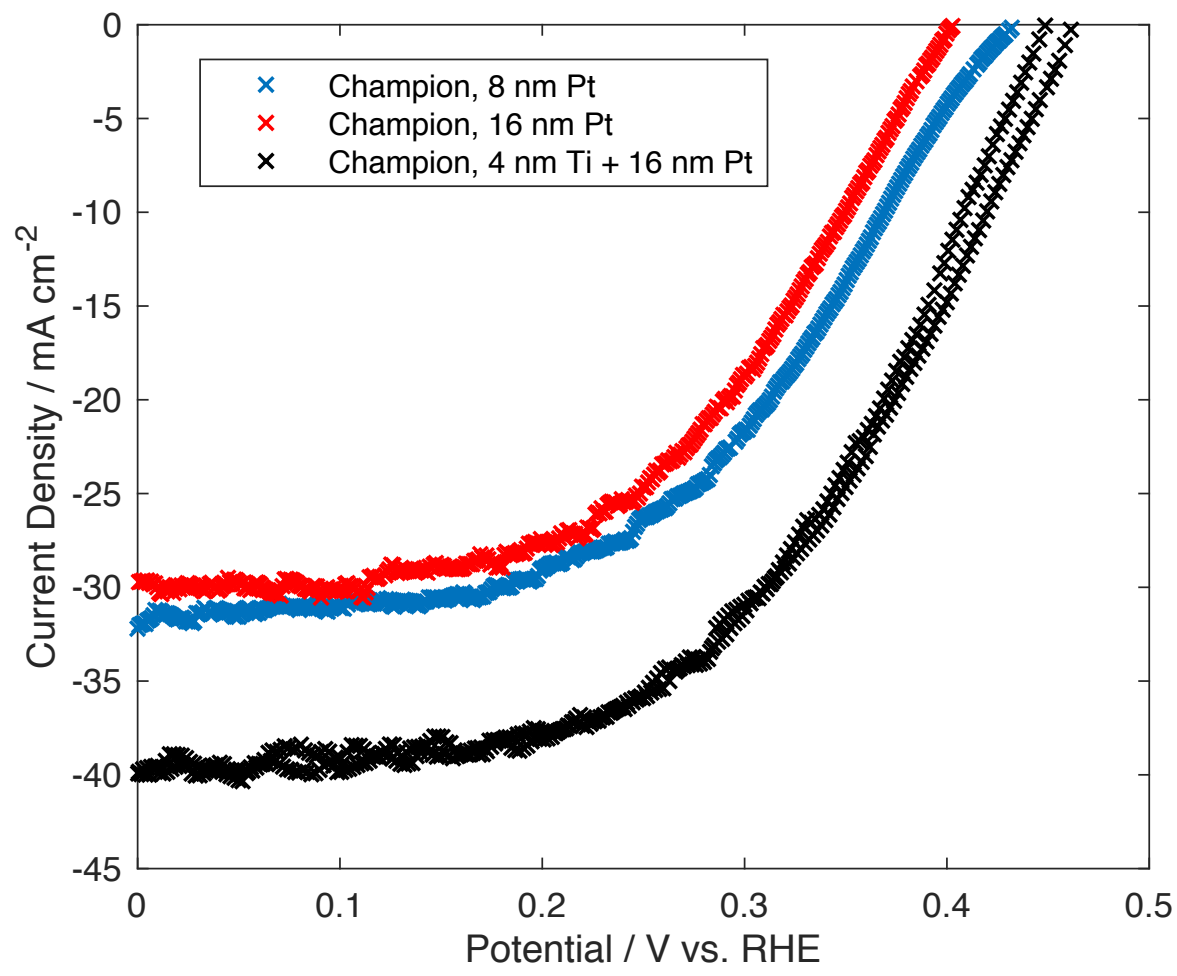

Figure S3: Initial performance (scan 1) of the best-performing $\mathrm{n}^{+} \mathrm{p}$-Si/Pt $\mu$-cone photocathodes with $8 \mathrm{~nm}$ or $16 \mathrm{~nm}$ thick Pt loaded on the tips of the $\mu$-cones. The photocathodes were tested in $\mathrm{H}_{2}$-saturated $0.50 \mathrm{M} \mathrm{H}_{2} \mathrm{SO}_{4}(\mathrm{aq})$ under $100 \mathrm{~mW} \mathrm{~cm}^{-2}$ of simulated AM1.5 illumination, with rapid stirring of the electrolyte to remove bubbles from the electrode surface. 

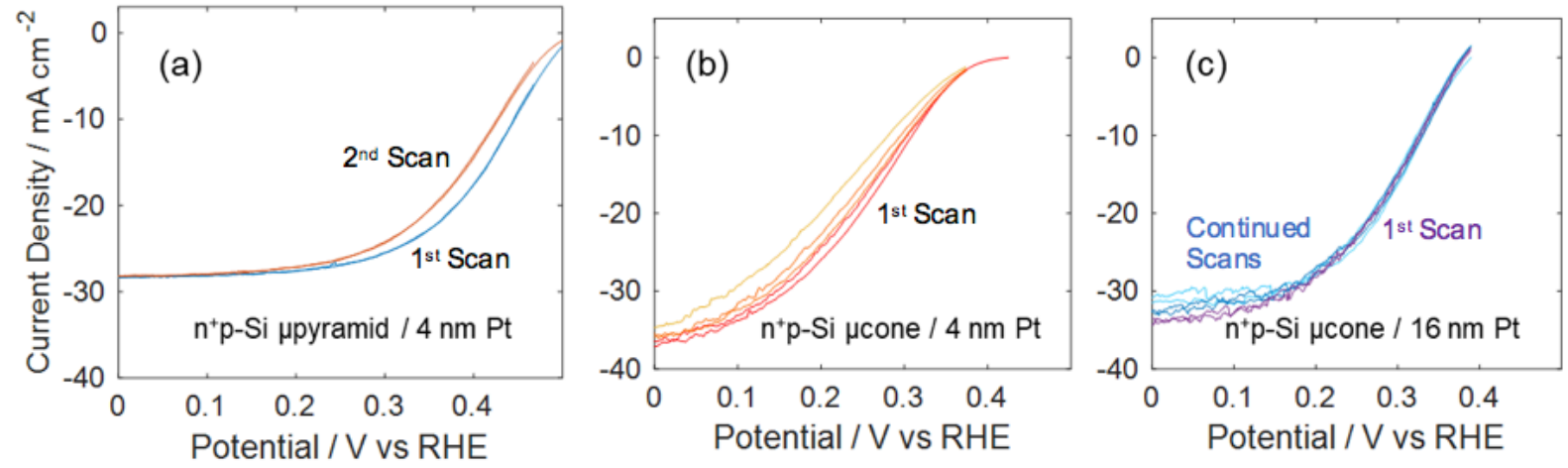

Figure S4: Stability of $\mathrm{n}^{+} \mathrm{p}$-Si/Pt photocathodes operated in contact with $\mathrm{H}_{2}$-saturated $0.5 \mathrm{M}$ $\mathrm{H}_{2} \mathrm{SO}_{4}$ (aq) while under $100 \mathrm{~mW} \mathrm{~cm}{ }^{-2}$ of simulated AM1.5 illumination. For ${ }^{+} \mathrm{p}-\mathrm{Si} / \mathrm{Pt} \mu$-pyramid photocathodes with (a) $4 \mathrm{~nm}$ of Pt, a decrease in fill factor (red trace) was observed after the first potential scan (blue trace). For $n^{+} \mathrm{p}-\mathrm{Si} / \mathrm{Pt} \mu$-cones, devices with (b) $4 \mathrm{~nm}$ of Pt on the $\mu$-cone tips showed a decrease in fill factor with successive scans (yellow traces), whereas devices with (c) $16 \mathrm{~nm}$ of Pt did not show an improvement in $J_{\mathrm{ph}}$ and no decay in fill factor (blue traces) after the first scan (purple trace). 


\section{Extended Methods}

Stability testing: Extended stability testing of $\mathrm{n}^{+} \mathrm{p}-\mathrm{Si} / \mathrm{Ti} / \mathrm{Pt}$ and $\mathrm{p}-\mathrm{Si} / \mathrm{Co}-\mathrm{P} \mu$-cone arrays was performed under nominally identical conditions as those used for photoelectrochemical testing, but with a Pt mesh electrode counter electrode behind a Nafion membrane (Fuel Cell Store). $\mathrm{H}_{2}$ was bubbled through the electrolyte for the duration of the stability tests to maintain a dissolved concentration of $\mathrm{H}_{2}$ in equilibrium with 1 atmosphere of $\mathrm{H}_{2}(\mathrm{~g})$.

Electrochemical impedance spectroscopy: Electrochemical impedance spectra were measured under nominally identical conditions to those used in photoelectrochemical testing. A sinusoidal perturbation of amplitude $25 \mathrm{mV}$ was applied to the potential of the working electrode and the impedance response was recorded over a frequency range from $7 \mathrm{MHz}$ to $20 \mathrm{~Hz}$. 

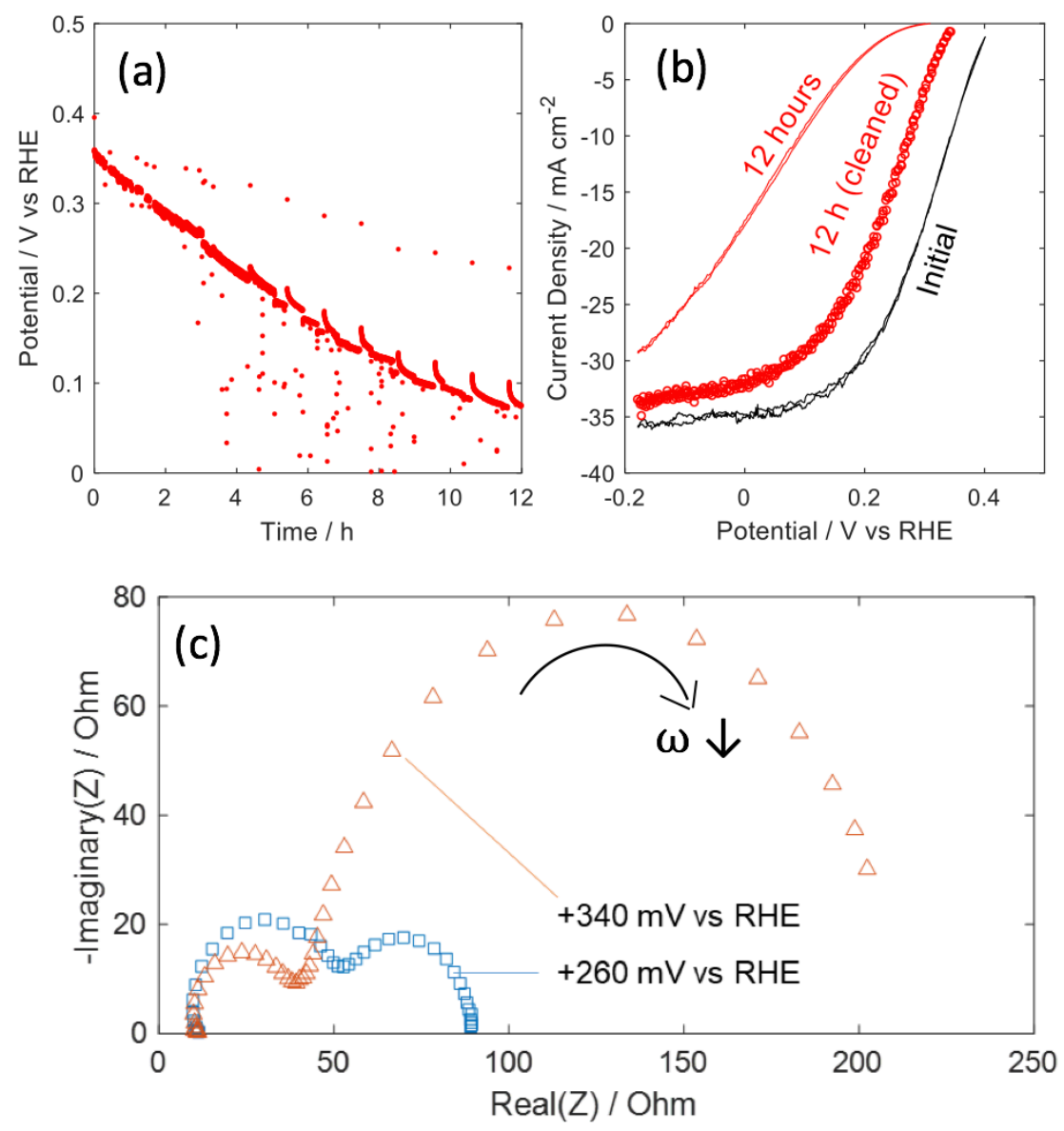

Figure S5: Stability testing of $\mathrm{n}^{+} \mathrm{p}$-Si/Pt $\mu$-cone array photocathodes in $\mathrm{H}_{2}$ purged $0.50 \mathrm{M}$ $\mathrm{H}_{2} \mathrm{SO}_{4}$ (aq) under 1-Sun illumination. (a) Chronopotentiometry at $-10 \mathrm{~mA} \mathrm{~cm}$-2 for $12 \mathrm{~h}$. Cyclic voltammograms were periodically recorded at $50 \mathrm{mV} \mathrm{s}^{-1}$ to monitor the $J-E$ behavior of the device. (b) $J-E$ behavior of a representative photocathode before testing (black line), after $12 \mathrm{~h}$ of chronopotentiometry at $-10 \mathrm{~mA} \mathrm{~cm}$ (red line), and after $10 \mathrm{~s}$ in aqua regia and rinsing with copious deionized water (red circles). (c) Nyquist plot for an $\mathrm{n}^{+} \mathrm{p}$-Si/Pt $\mu$-cone array photocathode after testing, recorded under 1-Sun illumination, in $0.5 \mathrm{M} \mathrm{H}_{2} \mathrm{SO}_{4}(\mathrm{aq})$, over a frequency range of $2 \mathrm{MHz}$ to $20 \mathrm{~Hz}$, at $+260 \mathrm{mV}$ (orange) and $+340 \mathrm{mV}$ (blue) vs RHE. 


\section{Stability testing: Results and Discussion}

A comparison of the $J-E$ behavior of the device before and after $12 \mathrm{~h}$ of chronopotentiometry (Figure S5a) revealed that the fill factor degraded during extended operation at negative potentials relative to open-circuit (Figure S5b). Cleaning the device via a $10 \mathrm{~s}$ dip in 3:1 (vol) hydrochloric acid and nitric acid, and rinsing with copious deionized $\mathrm{H}_{2} \mathrm{O}$, restored a substantial fraction of the initial fill factor. The presence of a $4 \mathrm{~nm} \mathrm{Ti}$ adhesion layer in $\mathrm{n}^{+} \mathrm{p}$-Si/Ti/Pt $\mu$-cone array photocathodes did not affect the stability of the catalyst layer. Furthermore, comparisons of SEMs of devices before and after $12 \mathrm{~h}$ of continuous testing in $0.50 \mathrm{M} \mathrm{H}_{2} \mathrm{SO}_{4}$ (aq) did not reveal changes to the morphology or coverage of the Ti/Pt layer during extended operation (Figure S6). Thus, the loss in $V_{-10}$ can be attributed to reduced activity of the thin metal film and not to delamination or loss of catalyst material.

The frequency-dependent impedance response for $\mathrm{n}^{+} \mathrm{p}$-Si/Pt $\mu$-cone array photocathodes is plotted in Figure S5c. Two distinct semicircles were observed when plotting the negative of the imaginary component of the impedance against the real component of the impedance, a Nyquist Plot. Semicircles that can be separated by frequency indicate the presence of multiple charge trapping regions which exhibit time constants differing by at least an order of magnitude. ${ }^{6}$ Such a response has been reported previously at silicon and hematite photoelectrodes decorated with catalysts. $^{6,7}$ Multiple equivalent circuits can be fit to this response. An unambiguous assignment of the individual capacitances and resistances could be achieved by a systematic variation of doping concentration and catalyst coverages at the devices; this is beyond the focus of the present study. In the high-frequency limit, the impedance contribution from capacitance is minimized such that the total impedance is dominated by the ohmic resistance of the cell, which was $\sim 10$ ohms. In the low-frequency limit, the impedance of all capacitances is large. and the real component of the impedance approaches the direct current polarization resistance of the cell. At all potentials, the polarization resistance was larger than the series resistance. 


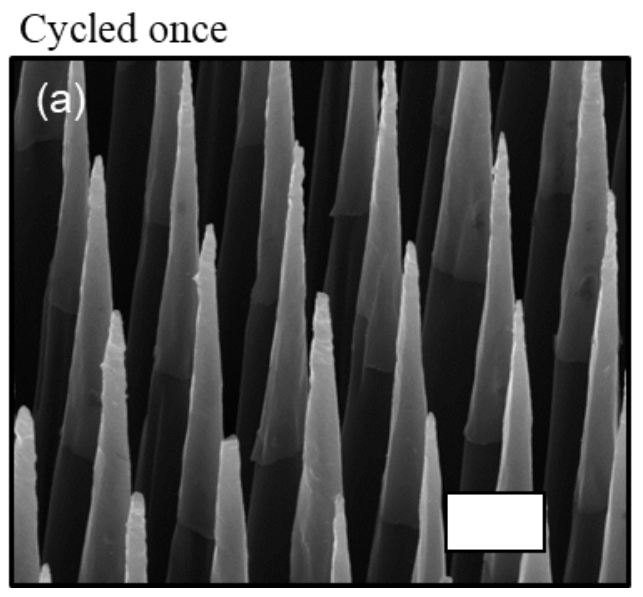

12 hours at RHE

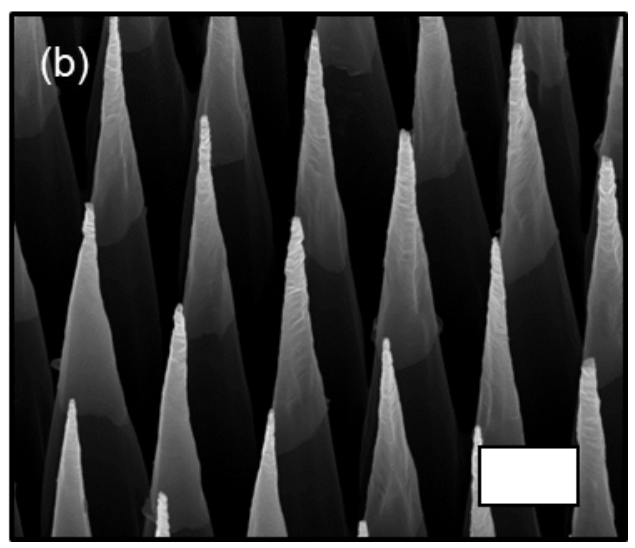

Figure S6: SEM images at $10 \mathrm{kV}$ and 30 degree sample tilt of $\mathrm{n}^{+} \mathrm{p}-\mathrm{Si} / \mathrm{Ti} / \mathrm{Pt} \mu$-cone array photocathodes (a) before and (b) after $12 \mathrm{~h}$ of chronoamperometric testing in $0.50 \mathrm{M} \mathrm{H}_{2} \mathrm{SO}_{4}(\mathrm{aq}$ ) under simulated AM1.5 illumination at RHE. Scale bars represent $5 \mu \mathrm{m}$ at 0 degrees tilt. 


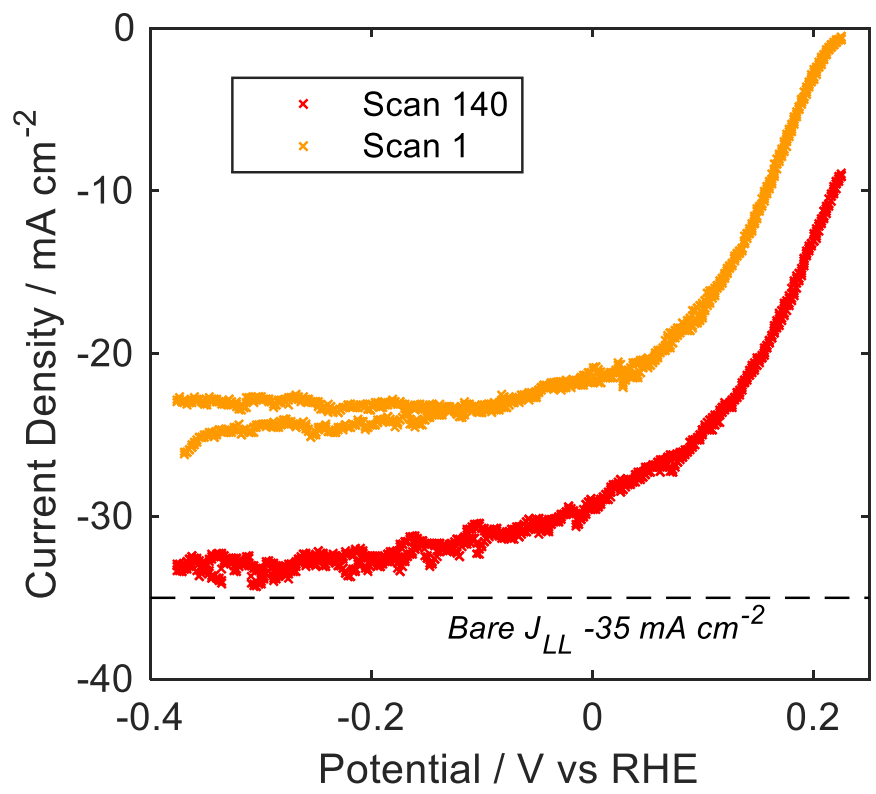

Figure S7: $J-E$ behavior of the best-performing $\mathrm{p}-\mathrm{Si} / \mathrm{CoP} \mu$-cone photocathodes with $400 \mathrm{mC}$ $\mathrm{cm}^{-2}$ Co-P deposited photoelectrochemically. The device was cycled from the initial open-circuit potential to $-0.376 \mathrm{~V}$ vs RHE in $\mathrm{H}_{2}$-saturated $0.50 \mathrm{M} \mathrm{H}_{2} \mathrm{SO}_{4}$ (aq) under $100 \mathrm{~mW} \mathrm{~cm}{ }^{-2}$ of simulated AM1.5 illumination, with rapid stirring of the electrolyte to remove bubbles from the electrode surface. 

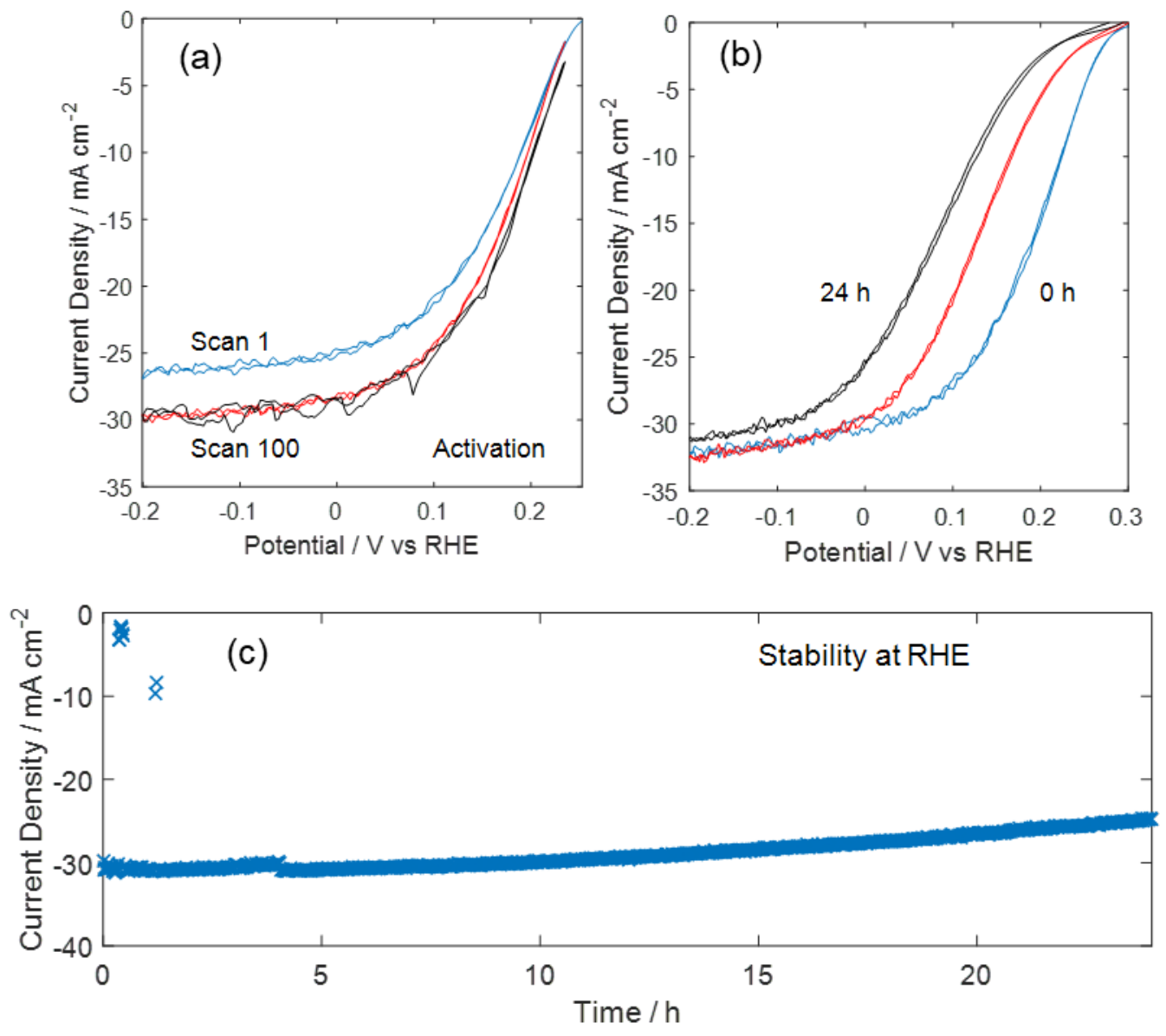

Figure S8: Extended photoelectrochemical testing of a p-Si/CoP $\mu$-cone photocathode with 400 $\mathrm{mC} \mathrm{cm}{ }^{-2}$ Co-P. (a) Current density vs potential behavior in $\mathrm{H}_{2}$-saturated $0.50 \mathrm{M} \mathrm{H}_{2} \mathrm{SO}_{4}$ (aq) under $100 \mathrm{~mW} \mathrm{~cm}^{-2}$ of simulated AM1.5 illumination, with rapid stirring of the electrolyte for the $1^{\text {st }}$, $10^{\text {th }}$, and $100^{\text {th }}$ cycle at $50 \mathrm{mV} \mathrm{s}^{-1}$, blue, red, and black circles, respectively. The $100^{\text {th }} \mathrm{scan}$ occurred after $30 \mathrm{~min}$ of cycling. (b) Comparison of the $J-E$ behavior over $24 \mathrm{~h}$ of continuous $\mathrm{H}_{2}(\mathrm{~g})$ evolution at RHE under 1-Sun illumination for the device activated in (a). The initial, $12 \mathrm{~h}$, and $24 \mathrm{~h} J-E$ behavior is shown in blue, red, and black respectively. (c) Chronoamperometry trace for the device activated in (a). 
As Deposited

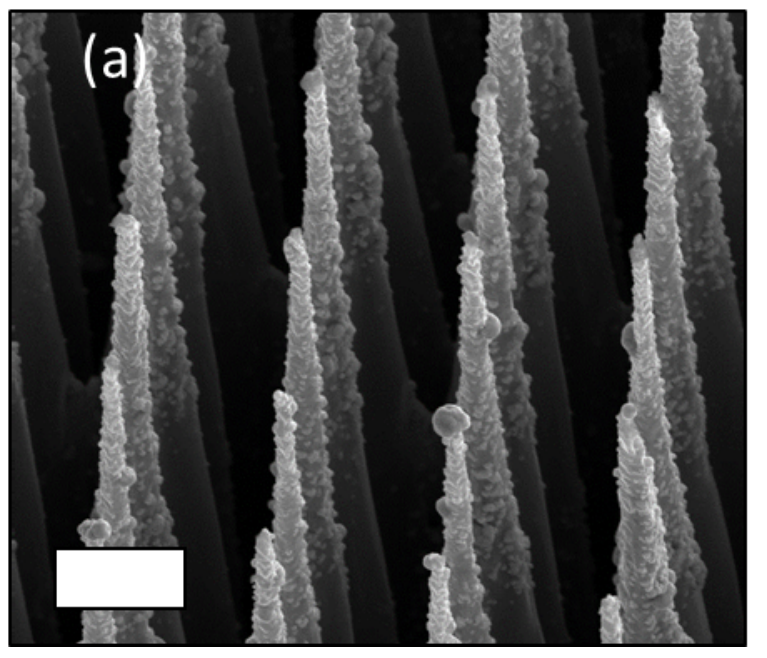

24 hours in $0.5 \mathrm{M} \mathrm{H}_{2} \mathrm{SO}_{4}$

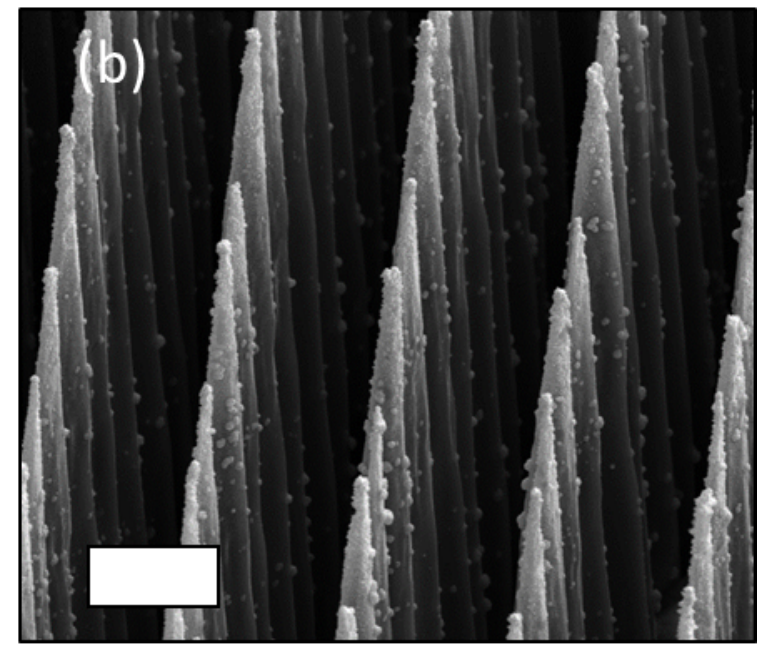

Figure S9: Scanning-electron micrographs of the $\mathrm{p}-\mathrm{Si} / \mathrm{CoP} \mu$-cone photocathode with $400 \mathrm{mC}$ $\mathrm{cm}^{-2}$ Co-P before (A) and after (B) testing in $0.50 \mathrm{M} \mathrm{H}_{2} \mathrm{SO}_{4}(\mathrm{aq})$ under 1-Sun illumination for 24 h. Scale bars represent $5 \mu \mathrm{m}$ at 0 degrees tilt.

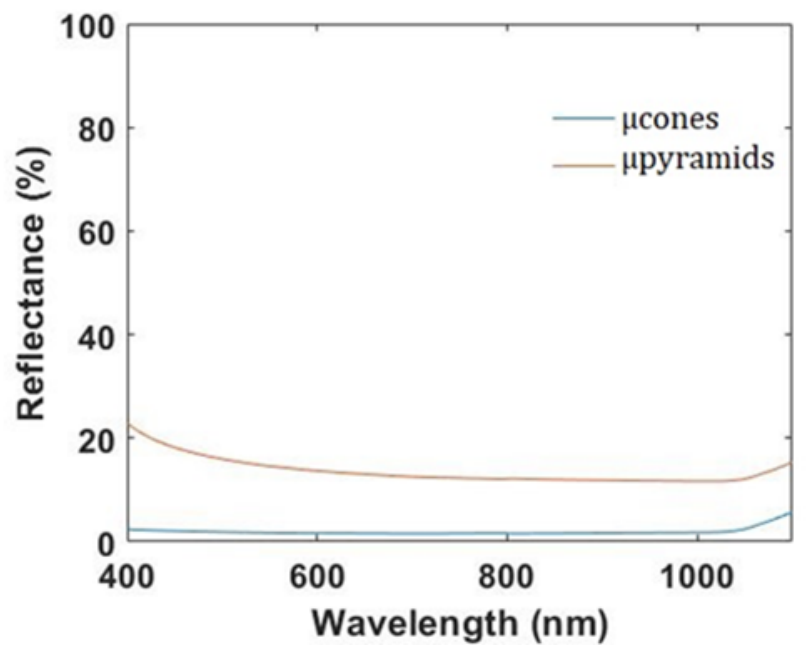

Figure S10: Comparison of reflection from bare Si $\mu$-pyramids and bare Si $\mu$-cones as measured using a Cary 5000 UV-VIS spectrometer with an integrating sphere. 


\section{Supporting References}

1. K. T. Fountaine, W.-H. Cheng, C. R. Bukowsky and H. A. Atwater, ACS Photonics, 2016, 3, 1826-1832.

2. T. Mårtensson, M. Borgström, W. Seifert, B. Ohlsson and L. Samuelson, Nanotechnology, 2003, 14, 1255.

3. C. T. Chen, D. B. Turner-Evans, H. Emmer, S. Aloni and H. A. Atwater, 2013 IEEE 39th Photovoltaic Specialists Conference (PVSC), 2013.

4. M. R. Shaner, M. T. McDowell, A. Pien, H. A. Atwater and N. S. Lewis, J. Electrochem. Soc., 2016, 163, H261-H264.

5. M. R. Shaner, K. T. Fountaine, S. Ardo, R. H. Coridan, H. A. Atwater and N. S. Lewis, Energy Environ. Sci., 2014, 7, 779-790.

6. D. Klotz, D. A. Grave, H. Dotan and A. Rothschild, J. Phys. Chem. Lett, 2018, 9, 14661472.

7. H. Zhang, Q. Ding, D. He, H. Liu, W. Liu, Z. Li, B. Yang, X. Zhang, L. Lei and S. Jin, Energy Environ. Sci., 2016, 9, 3113-3119. 